\title{
НАЦИОНАЛЬНЫЕ ИГРЫ НАРОДА САХА КАК ЧАСТЬ ТРАДИЦИОННОЙ КУЛЬТУРЫ
}

\author{
Аммосова Марфа Федотовна \\ студент кафедры народной \\ художественной культуры \\ Научный руководитель: Стрекаловская Зоя Андреевна \\ кандидат культурологии, доцент \\ и.о. зав. кафедрой народной художественной культуры \\ ФГБОУ ВО «Арктический государственный \\ институт культуры и искусств»
}

Аннотация: Статья посвящена национальным играм народа саха. Национальные игры народа Саха продолжают оставаться актуальными и в современное время. В последние годы наблюдается все возрастающий интерес народа к освоению народных игр. А это значит, что люди хотят знать свою культуру, свои истоки, свои традиции. В таких моментах, к началу пути саморазвития, к популяризации традиционного выполнения якутских народных игр непосредственно может стать якутский героический эпос олонхо, где подробно описаны первоначальные названия и способы выполнения национальных игр народа Саха. Фольклорные сведения указывают на достоверность происходящего в его историческом пространстве. Память через устную традицию четко фиксирует и высвечивает все нюансы этнического бытия, в том числе и в области национальных игр.

Ключевые слова: олонхо, национальные игры, фольклор, традиционная культура, текст олонхо, якуты, саха, спортивные игры, настольные игры, хабылык, хаамыска, хапсагай, мас-рестлинг, конские скачки, кылыы, кылыйсыы, тустуу, сыал ытыы.

\section{NATIONAL GAMES OF THE SAKHA PEOPLE AS PART OF TRADITIONAL CULTURE}

\author{
Ammosova Marfa Fedotovna \\ Strekalovskaya Zoya Andreyevna
}


Abstract: The abstract is devoted to the national games of the Sakha people. The national games of the Sakha people continue to be relevant in modern times. In recent years, there has been an increasing interest of the people in the development of folk games. And this means that people want to know their culture, their origins, their traditions. At such moments, the Yakut heroic epic - olonkho, which describes in detail the original names and methods of performing the national games of the Sakha people, can directly become the beginning of the path of self-development, to popularize the traditional performance of the Yakut folk games. Folklore information indicates the authenticity of what is happening in its historical space. Memory through oral tradition clearly captures and highlights all the nuances of ethnic existence, including in the field of national games.

Key words: olonkho, national games, folklore, traditional culture, text of olonkho, yakut, sakha, sports games, board games, khabylyk, khaamiska, khapsagai, mas-wrestling, horse racing, kylyy, kylyisyy, tustuu, syal ytyy.

Народные игры сочетают в себе прошлое и настоящее наследие наших предков. Поэтому они играют важную роль в развитии и расширении творческих способностей подрастающего поколения, укреплении их здоровья и изучении традиций.

Как нам известно, якуты издавна свое свободное время проводили за играми и развлечениями. Зимой день был коротким, а ночь длинным, поэтому якуты играли до поздней ночи. Особенно когда к ним издалека приходили гости с ночевкой. Они разговаривали, рассказывали разные истории и играли в якутские народные игры.

Якутские национальные игры в основном бывают двух видов: подвижными, где относятся спортивные и уличные игры, и настольными.

К якутским подвижным играм по классификации И.А. Худякова относятся: утки и гуси «кустаах-хаастаах», волк и жеребец «бөрө, атыыр буолар», жеребята «кулун куллуруһар», прыганье «ыстаналыы», кылыйыы, мас тардыһар и др. К настольным играм относятся «Хабылык», «Хаамыска», «Тырыынка» , «Тыксаан» Юлка (өртөгөй), Волчок (күүгүнэс), Луобат (шашки), Карты и др. [16, с. 149-157].

Первым якутом, который описал национальные игры народа Саха является А.Е. Кулаковский. В журнале «Записки Якутского краеведческого географического общества» имеются его фольклорные материалы под названием «Материалы для изучения верований древних якутов». В них 
описано, как старый воин Тисикян показывает мастер класс по прыжкам на одной ноге «кылыы», ухода с линии атаки от удара пальмой, и убийство им одного из братьев богатырей в ходе борьбы хапсагай [7, с. 5-21].

Одной из составных частей якутского героического эпоса - олонхо являются национальные игры народа саха. Не случайно во всех сказаниях, легендарных преданиях якутского народа главными героями являются люди, обладающие физическим преимуществом над другими людьми.

В 1927 году Платон Алексеевич Ойунский в «Сборнике трудов исследовательского общества «Саха кэскилэ» опубликовал большую статью «Якутские сказки (олонхо), ее сюжет и содержание». В этой статье имеется глава «Виды состязаний». В ней рассматриваются состязания богатырей, героев якутского героического эпоса - олонхо.

П.А. Ойунский рассматривает четыре вида состязаний: 1) «Кылыйсыы» - прыжки на одной ноге, не менее чем через 12 меток. В исключительных случаях эти прыжки происходят по столбам, поставленным в озеро. 2) «Тустуу» - единоборство, борьба. Побежденным считается также тот, кто коснется пальцем о землю, хотя бы споткнувшись. 3) «Сыал ытыы» попадание стрелою в цель из лука или из лука - самострела. 4) «Конские бега по трем мирам» [7, с. 19].

Для исследования якутских национальных игр в якутском героическом эпосе мы изучили три олонхо: олонхо П.А. Ойунского «Ньургун Боотур Стремительный», П.П. Ядрихинского «Дьырыбына Дьырылыатта Кыыс бухатыыр» и олонхо Д.М. Говорова «Непобедимый Мюльджю Бёгё», где подробно описана сила мышц и духа лучших представителей народа Саха, а также имеются информации о национальных играх народа саха, о развитии физической силы, выносливости и воли кандидатов в богатыри.

Например, в олонхо Прокопия Прокопьевича Ядрихинского-Бэдьээлэ «Дьырыбына Дьырылыатта Кыыс бухатыыр» встречается такой отрывок с национальными играми:

«...Кыыс о5о убайыныын

Толоонно киирэннэр

Тула сүүрэн сырыстахтарына,

Тулуппат буолан истэ;

Хабылыктыы оонньоотохторуна,

Хапсађайа билиннэ...

Маһы-оту былдьастахтарына 
Харса суох батарыта харбаан

Кыайа-хото туура тутар...» [20, с. 37].

В этом отрывке автор описывает то, как якутская богатырка Дьырыбына Дьырылыатта вместе со своим братом, богатырем Тойон Дьөллүүт по мере возрастания играют в хабылык, прыгают, бегают, учатся стрелять из лука, занимаются борьбой - хапсагай. Благодаря таким физическим нагрузкам, закалялся характер якутской богатырки.

В олонхо П.Е. Решетникова «Уордайа Хаан» описывается вторжение племен абаасы на Средний мир. Они предлагают устроить состязания по трем видам с условием: если победа будет на стороне абаасы, то они разрушат Средний мир, а если проиграют, то уйдут с миром. Племя айыы держит совет и решает согласиться. В первом состязании, в конных скачках, посыльный парень на коне Ала Джоруо одолевает восьминогого коня Нижнего мира Ала Могой:

«...Ити кэнниттэн

Үс көрүннэ күрэс былдьаһан,

Күөн көрсүөх буолан,

Арқаа-илин аадастаһа турдулар.

Аан бастаан

Ат сүүрдүүтэ буолар буолла...

...Икки аан дойду

Ааттаaх аттара

Атахтарын анныттан

Анысхан тыалы таһааран,

Туйахтарын анныттан

Тууспан холоругу тоқо ытыйан,

Үс сүллэр этин сүллүгэстэнэн,

АБыс сааллар чақылқан кымньыыланан,

Ала Моқой ат

Отут былас уот субурқа кутуруга,

Ала Дьоруо ат

Уон былас оночо куйаар кутуруга

Субуруйа Субуллан

Соқуруу халлаан улақатыттан

Субулла сүүрэн

Сундулуһан истэхтэрэ...» [12, с. 352-354]. 
Во втором состязании, в беге, соперники десять раз обегают Киэнг Килэдики Эбэ Хотун. Девка абаасы Сырбангса Сарасын, которую не могли догнать все быстроногие абаасы Нижнего мира, обгоняет Кытыгырас Бараанчай Боотур:

«...Күрэхтэһии иккис көрүнэр

Айыы уонна абааһы

Аймахтарыттан биирдии

Бэкийэр бэртэрин киллэрэн

Сырыһыннарар буоллулар...

...Кытыгырас Бараанчай Боотуру уонна

Сараһын кыыһын

Арыаллаан илдьэннэр,

Киэн Килэдики Эбэ Хотун хоннођор

Кэккэлии туруордулар.

Отут көс эргимтэлээх,

Түөрт уон көс төгүрүмтэлээх

Киэн Килэдики Эбэ Хотуну

Уон төгүлэ эргийэн

Биэтэги булуохтаах эбиттэр.

Ханас өттүлэриттэн

Адьарай атамаана,

Уна өттүлэриттэн

Ураанхай туйгуна

Хамаанда биэрэн

Хаһыытыылларын кытта,

Уоллаах кыыс

Унаар буруо курдук

Суос соқотохто Субурус гына түстүлэр.

Эрбии биитин курдук

Тэбис тэннэ эрийистилэр,

Сыарқа сынаађын курдук

Тэннэ тардыаластылар...» [12, с. 357-359].

В третьем состязании, в хапсагае, Уордаайы Хаан побеждает богатыря абаасы Уот Уһуму. В итоге в состязаниях побеждают богатыри Среднего мира. Приведем подробный пример из текста олонхо:

«...Айыы уонна абааһы 
Ааттаах бухатыырдара,

Сүүллэрэ киирэн

Күрдьүөттэһэ турар

Аарыма атыыр лБустар курдук,

Утары кииристилэр,

Уһун дьураа тарбахтарын төбөлөрүнэн

Тардыалаһан бардылар,

Таас сабарай ытыстарынан

Таннары баттастылар,

Эрчимнээх илиилэринэн

Эрийитэ тардыстылар.

Ол кэнниттэн

Хаһыытаһа-хаһыытаһа

Халбарыйсан бардылар,

Үөгүлэһэ-үөгүлэһэ

Өттүктэһэн көрдүлэр,

Орулаһа-орулаһа

Охторсо сатаатылар,

Үөл талах курдук

Үлтү муккустулар

Ириэнэх талах курдук

Ибили эрийистилэр.

Тустуу туйгуна туругурда.

Хапсыһыы хабыра сақаланна.

Кэмниэ-кэнэБэс, хомнуо хойут

Уордаах-кылыннаах

Уордайа Хаан бухатыыр

Адьарай ааттаађын

Ханас илиитинэн

Халбарыс гына анньан баран,

Уна илиитинэн

Сототун ортотуттан

Олуйа охсон ылан,

Үүттээх өттүгэр

Өрө мөБүһүннэрэн,

КөтөБөн таһааран, 
Үс саһаан үрдүк холобурдаађы

Өрө бырақан кууһуннарда...» [12, с. 360-361].

Также как пример можно привести олонхо Платона Алексеевича Ойунского «Ньургун Боотур Стремительный». В нем описывается предварительная тренировочная подготовка главного защитника Среднего мира, где он сначала выполняет прыжковые упражнения, работает с отягощениями (поворачивается, таскает тяжелые камни), а затем развивает ловкость, гибкость, решительность и подвижность в конных скачках.

Как в предыдущем параграфе было названо, в 1927 году Платон Алексеевич Ойунский в «Сборнике трудов исследовательского общества «Саха кэскилэ» опубликовал большую статью «Якутские сказки (олонхо), ее сюжет и содержание»., где он первым изучает якутские национальные игры в якутском героическом эпосе - олонхо. Давайте рассмотрим это по подробнее:

По исследованиям П.А. Ойунского соревнования силачей Срединного мира совершаются в главном национальном празднике якутов «ыһыах» у известных богачей-тойонов, прежних богатырей, имена которых грохочут на трех мирах.

Такие соревнования проводились не только для развлечения, но и для подготовки богатырей к борьбе против злых существ. Также состязания проводились для выявления лучшего жениха дочери устроителя праздника «ыһыах». Имя победителя «гремел на трех мирах, как гром, на всех путях мира», его слава «ржал, как жеребец, зовущий своих соперников на бай» [11. c. 18].

Победителя встречают перед юртой устроители «ыһыах» с приветственным кумысом в чороне двенадцать, как самки-стерхи, белых, белых, стройных и красивых девушек, а также двенадцать юношей, стройных, как журавли, сильных и здоровых; ему устилают путь «дэбдиргэ», ведут его за руки, открывают перед ним двери и отводят его на почетный «олбох».

Виды состязаний, которые выявил П.А. Ойунский в якутском эпосе олонхо:

1. «кылыйсыы» - прыжки на одной ноге, не менее чем через 12 меток. Метки называются «туос», т.е. берестой. Очевидно, метки клались из бересты, как более заметные и мягкие. В исключительных случаях эти прыжки происходят по столбам, поставленным в озеро.

2. «тустуу» - единоборство, борьба. Богатыри, вступающие в единоборство, снимают все свои доспехи, кольчуги, оружие и одежду. 
Им натирают маслом тело, на них надевают специальные «сыалдьыйа» проде трусиков, шитых из ровдуг, толшиной в девять ровдуг на подкладке и стягивают ремнями. Причем, эти ремни делаются из конских волос путем плетения. Толщина таких ремней равняется толщине трех или шести и девяти обычных. Побежденным считается также тот, кто коснется пальцем о землю, хотя бы споткнувшись.

3. «сыал ытыы» - попадание стрелою в цель из лука или из лука самострела. Обычно мишенью служит бычья бабка - «ођус бэрбээкэйэ». В олонхо во всех случаях эта бабка висит на восточном небе, на волшебной веревке - «ап чарай быақа», и движется с юга на север и обратно. Высота равняется предельной досягаемости человеческого зрения. Нужно попасть, разбить бабку на четыре части. попавший - попадает в свою судьбу: он женится.

4. Последним видом состязания являются конские бега по трем мирам «Үөһээ дойду», «Орто дойду», «Аллараа дойду». Кони богатырей понимают все значение этих соревнований, что жизнь, счастье и слава их хозяев зависят от их бега. Они прибегают к различным хитростям: передняя лошадь не дает пути последнему, ударяя его копытами. Идущий последним, если первых не уступает ему место, грызет ему бока или пускает пламя из ноздрей на его хвост и бока. Также иногда обращаются к духам с просьбой о подкреплении их силы и ловкости [11. с. 19].

Также нельзя не отметить, что некоторые спортивные виды соревнований можно встретить в военных состязаниях богатырей Среднего, Нижнего и Верхнего миров якутского эпоса олонхо. В основном к ним относятся борьба и конские бега. Такую тему исследовал П.А. Ойунский в своей работе «Якутская сказка (олонхо), ее сюжет и содержание». Он дает описание о «местах и способах борьбы богатырей из среднего мира с богатырями нижнего и верхнего миров».

В первом случае богатыри Среднего мира и Нижнего мира вступают в смертельную борьбу. Битва совершается или в среднем, или в нижнем мире. Также борьба может прекратиться бегством слабого, если есть к тому возможность. При равенстве сил обоих противников, когда они не расходятся миром и в результате учиняют многочисленные бедствия всем трем мирам, их силой отправляют на заднюю вершину Почтенной Горы, где «госпожа - луна, родившись, лежа нежилась» или на Серебряную Гору, «где господин солнце, родившись, кувыркалось». Эти горы находятся вне пределов трех 
миров, на востоке, против среднего, между нижним и верхним мирами. К этим горам богатыри отправляются на своих верных лошадях, догоняя друг друга. Борьба титанов дает себя знать и оттуда. Солнце и луна трех миров поворачиваются назад, бледнеют, наступает мрак, озаряемый лишь заревом от искр, сыплящихся от ударов богатырей. Конный и рогатый скот не доносят свой плод и разрешаются недоносками; то же случается и с женщинами из «айыы аймађа».

Но борьба и на этом месте не является разрешающей. Сражающихся разнимают волшебным арканом и бросают нижний мир, на северо-западный его край в страну смерти и бедствий «Чөркөчүөх төрдүгэр». В этой стране имеется кровавое, огне-бурное море «Хааннаах Уот Кудулу байБал», в середине которого вырос волшебный, остроконечный крутящийся курган смерти «өлүҮ мөБҮүк булгунньађа», созданный удаганкой-волшебницей «Уот Чүкүрүйдээн эмээхсин» [11, с. 20].

Битву начинает богатырь Нижнего мира, а заканчивает богатырь Среднего мира. При падении богатыря из Среднего мира, «Айыы Умсуур» подставляет ему свой волшебный бубен и спасает. Спасенный продолжает битву и бросает своего врага в море. Удаганка богатыря Нижнего мира «Уот Хахайдаан», желая показать, что и она может так же спасти своего богатыря, тоже подставляет ему бубен. Она не предвидела коварства своей соперницы, ее бубен прорывается и сын Нижнего мира поглощается божеством его же страны [11, с. 20].

Богатыри из Среднего и Верхнего миров (последний всегда является из «Абааһы бииһин ууһуттан»), обычно вступают в битву на территории Среднего мира, причем местом битвы для них является каменное плоскогорье, находящееся под южным небом. Это самое знаменитое поле-побоище, омытое кровью, покрытое костями, где вокруг стоят колья с одетыми на них черепами.

В случае равенства соперников, когда их борьба причиняет неисчислимые бедствия срединному миру, все духи и божества среднего мира обращаются к" Белому Пожилому Мастеру " с просьбой перенести соперников в другое место. Сражающихся ловят волшебным арканом и, если они отказываются разрешить свой спор мирным путем, их отправляют в те же горы солнца и луны. Причем богатыри из верхнего и нижнего миров, из «абааһы аймақа» всегда прибегают к обману, обрисовывая положение так, что они не защищаются от обид и несправедливости слишком зазнавшихся сынов 
среднего мира. На новом месте борьбы богатырь из «абааһы аймақа», когда он чувствует превосходство своего врага, прибегает к мирному средству разрешения спора. Богатырь из среднего мира, чувствующий свое превосходство, не соглашается с предложением своего противника. Богатырь из «абааһы аймаБа», обругав и оскорбив еще сильнее своего врага, обращается в бегство, стараясь скрыться в верхнем мире. Он надеется, что трудности пути будут непреодолимыми и остановят противника. Но богатырь из среднего мира гонится за ним, уже разъяренный вдвойне.

Борьба обоих врагов в верхнем мире доставляет всем трем мирам непереносимые муки. Эту борьбу не выносит даже господин шести небесных стран «Үрүн Айыы Тойон». Богатырь, выигравший борьбу в нижнем и верхнем мирах, признается великим на всех трех мирах, и если он достигает своего последнего предела, то признается равным титаном мира, величайшим богатырем на трех мирах $[11$, с. 20].

Таким образом, можно сделать вывод, что национальные игры народа саха играют огромную роль в становлении сюжета якутского героического эпоса - олонхо. Они встречаются в описаних якутского национального праздника Ысыах, которые проводят жители Срединного мира. Жители соревнуются для выявления сильнейшего богатыря в трех мирах, а также для того, чтобы завоевать сердце любимой женщины. Также в олонхо национальные игры являются элементом тренировочной подготовки богатырей. По исследованиям П.А. Ойунского национальные игры были вовлечены и в военное дело.

Собрав все эти исследования воедино, можно сделать вывод, что национальные игры народа саха играют огромную роль в сохранении и популяризации традиционной культуры. О них упоминают в якутском героическом эпосе олонхо, а также в легендах и преданиях народа саха, что еще раз показывает их огромную значимость в становлении якутской культуры. Сейчас идет огромная работа для ревитализации народных игр, путем институционализации и проведения различных мероприятий, спартакиад и т.п. Надеемся, что эта работа будет направлена на дальнейшее изучение и популяризацию национальных игр народа саха. 


\section{Список литературы}

1. Алексеев М.В. Историко-культурное и спортивно-прикладное развитие национальных видов спорта в России: опыт регионов / М.В. Алексеев. - Якутск, 2009. - 323 с.

2. Википедия. Институционализация [Электронный ресурс]. https://ru.wikipedia.org/wiki/Институционализация (Дата обращения: 28.05.2021).

3. Захарова А.Е. Якутский героический эпос олонхо: сохранение, изучение и развития / А.Е. Захарова, У.М. Флегонтова. - Якутск: Алаас, 2020. $-472 \mathrm{c}$.

4. Игры Дыгына - самое зрелищное спортивное состязание Ысыаха Туймаады [Электронный ресурс]. - Режим доступа: https://sakhalife.ru/igryidyigyina-samoe-zrelishhnoe-sportivnoe-sostyazanie-yisyiaha-tuymaadyi/ (Дата обращения: 21.05.2021).

5. Игры Манчаары [Электронный ресурс]. - Режим доступа: https://manchaars.ru/ (Дата обращения: 28.05.2021).

6. Ким-Кимэн А.Н. Концепция развития национальных видов спорта в Республике Саха (Якутия) / А.Н. Ким-Кимэн // II Республиканская научно-практическая конференция "Национальные виды спорта, народные игры в современной системе физического воспитания и образования. Якутск, 2002. - С. 3.

7. Кочнев В.П. Возрождая традиции предков - Өбүгэлэрбит үгэстэрин тилиннэрэн / В.П Кочнев., И.Ю. Григорьев., В.П. Коротов. - Якутск: Медиа-холдинг “Якутия”, 2009. - 324 с.

8. Кочнев В.П. Первые шаги физкультурного движения (1923-1930) / В.П. Кочнев // История физкультурного движения в Якутии: материалы конференции к 75-летию физкультурного движения в Якутии. - Якутск, 1998. - C. 5-21.

9. Линденау Я.И. Описание народов Сибири (первая половина XVIII века) / Я.И. Линденау. - Магадан: Кн. изд-ва, 1983. - 182 с.

10. Маак Р.К. Вилюйский округ Якутской области / Р.К. Маак. Москва: Яна, 1994. - 592 с.

11. Ойунский П.А. Якутская сказка (олонхо), ее сюжет и содержание / П.А. Ойунский. - Якутск, 2013. - 96 с.

12. Решетников П.Е. Айыы Дьурақастай. Уордайа Хаан / П.Е. решетников. - Якутск: Кытыл, Медиа-Холдинг Якутия, 2019. - 416 с. 
13. Серошевский В.Л. Якуты: опыт этнографического исследования / В.Л. Серошевский. - М., 1993. - 744 с.

14. Суровецкий Е.К. Сборник руководящих материалов по физкультурной работе на селе / Е.К. Суровецкий. - Якутск, 1945. - 58 с.

15. Торговкин В. Г. Физическое самосовершенствование юных борцов в традициях народа Саха / В.Г. Торговкин, И.И. Портнягин // Высшее образование сегодня. - 2014. - № 5. - С. 81-84.

16. Худяков И.А. Краткое описание Верхоянского округа / И.А. Худяков. - Ленинград: Наука, 1969. - 448 с.

17. Ысыах в описании И. Яхонтова // Г.Ф. Миллер. Сочинения. Описание якутского праздника Ысыах (31.05.1737). - Режим доступа http://drevlit.ru/texts/m/Miller_1/text2.php (15.05.2021).

18. Ысыах в описании Г.Ф. Миллера / Г.Ф. Миллер Сочинения. Описание якутского праздника Ысыах (31.05.1737). - Режим доступа http://drevlit.ru/texts/m/Miller_1/text2.php (15.05.2021).

19. Эргис Г.У. Очерки по якутскому фольклору / Г.У. Эргис. - М.: Наука, 1974. - 393 с.

20. Ядрихинский П.П. Дьырыбына Дьырылыатта Кыыс бухатыыр: олонхо / П.П. Ядрихинский. - Якутск: Якутское книжное изд-во, 1981. - 200 с.

21. Ядрихинский П.П. Дьырыбына Дьырылыатта кыыс бухатыыр. Девушка богатырь Джырыбына Джырылыатта / П.П. Ядрихинский. - Якутск: Сайдам, 2011. - 448 с.

22. Яковлев Я.И. Развитие национальных игр народа Саха с 30-х до 50-х годов XX века / Я.И. Яковлев, М.И. Борохин, А.В. Черкашин // Ученые записки университета им. П.Ф. Лесгафта. - 2019. - № 7(173). - С. 227-230.

23. Яковлев Я.И. Хронология изучения национальных игр Саха с первой половины 18 века до 30-х годов 20 века / Я.И. Яковлев, М.И. Борохин, И.И. Друзьянов // Ученые записки университета им. П.Ф. Лесгафта. - 2019. № 4(170). - С. 383-388. 